\title{
Carotid intima-media thickness in young patients with familial hypercholesterolaemia
}

\author{
Aleša Lavrenčič, Barbara Kosmina, Irena Keber, Viktor Videčnik, Dušan Keber
}

\begin{abstract}
Objective-To assess the extent of early atherosclerotic changes of the carotid arteries in young patients with familial hypercholesterolaemia (FH) detected as increased intima-media thickness (IMT), and to determine the relations between IMT and some clinical and blood variables such as lipid and lipoprotein(a) $(L p(a))$ concentration and haemostatic factors.

Design-The IMT of the carotid bifurcation, the proximal $1 \mathrm{~cm}$ of the internal carotid artery, and the distal $1 \mathrm{~cm}$ of the common carotid artery was determined in all subjects using $B$ mode ultrasonography. Blood lipids, fasting glucose, and several haemostatic variables were also analysed.
\end{abstract}

Subjects-28 patients with FH (12 males and 16 females aged 11 to 27 years, one homozygote, 27 heterozygotes) and $28 \mathrm{sex}$ and age matched normolipidaemic healthy subjects.

Results-The mean carotid IMT (the average of six measurements of the maximum far wall IMT in the three carotid segments on each side) was significantly greater in patients with FH than in controls (mean (SD) $0.71(0.15) v 0.49(0.08)$ $\mathrm{mm}, \mathbf{P}<0.001)$. In all subjects, the mean IMT was significantly correlated with total cholesterol $(r=0.59)$, low density lipoprotein (LDL) cholesterol $(r=0 \cdot 60)$, triglycerides $(r=0 \cdot 27)$, and systolic blood pressure $(r=0 \cdot 47)$. No correlation was found between the mean IMT and Lp(a), fibrinogen, tissue plasminogen activator, and plasminogen activator inhibitor 1.

Conclusions-The majority of young patients with FH have a greater intimamedia thickness of the carotid arteries than healthy subjects. Since the individual susceptibility of patients with FH to increased LDL cholesterol is different, $B$ mode ultrasonography could provide a useful tool to identify those who are more likely to develop premature atherosclerotic disease.

(Heart 1996;76:321-325)

Keywords: familial hypercholesterolaemia; carotid intima-media thickness; ultrasonography; fibrinolysis.

Familial hypercholesterolaemia $(\mathrm{FH})$ is a dominantly inherited disorder caused by mutation of the low density lipoprotein (LDL) receptor gene, resulting in high concentrations of serum LDL cholesterol in early childhood, accelerated atherosclerosis, and premature coronary heart disease. ${ }^{1}$ Early atherosclerotic changes of the arterial wall detected as increased intima-media thickness (IMT) can be studied by $\mathrm{B}$ mode ultrasonography. ${ }^{23}$ Because of the association between coronary and carotid artery atherosclerosis and the easy access of the carotid arteries to ultrasound scanning, the examination of extracranial carotid arteries can be used to predict the extent of atherosclerotic involvement of coronary arteries. ${ }^{4-6}$ Several investigators have looked for an association between various atherogenic risk factors and intima-media thickening of the carotid arteries by ultrasonographic measurement of IMT. Most studies have been made in middle aged and older subjects, ${ }^{7-9}$ while similar attention has not been paid to adolescents and young adults. This would be of particular interest in young patients with $\mathrm{FH}$ in whom the development of atherosclerotic lesions is an early event. The objectives of the present study were to compare IMT of the carotid arteries between young patients with $\mathrm{FH}$ and well matched healthy controls, and to determine the relations between IMT and some clinical and blood variables, such as lipid and lipoprotein(a) $(\mathrm{Lp}(\mathrm{a}))$ concentration and haemostatic factors.

\section{Methods}

SUBJECTS

Twenty eight young patients with $\mathrm{FH}$ (27 heterozygous and one homozygous) of both sexes (12 males and 16 females) and mean age of 20 years (range 11 to 27 years) were selected among the offspring of patients regularly controlled in a lipid clinic. Heterozygous FH was diagnosed on the basis of raised serum LDL cholesterol and normal triglyceride level according to the criteria of Williams et al, ${ }^{10}$ based on the age of the subjects and the presence of confirmed $\mathrm{FH}$ in close relatives. The diagnosis of the single case of homozygous $\mathrm{FH}$ was based on a serum total cholesterol level above $15 \mathrm{mmol} / \mathrm{l}$ and the presence of xanthomata before the age of $20 .{ }^{11}$ The homozygous patient had had tendon and planar xanthomata before she was treated with LDL apheresis, and her total cholesterol concentration at that time was $19 \mathrm{mmol} / \mathrm{l}$. By the time of the enrolment in the study the xanthomata had regressed and the concentration of total cholesterol had fallen to $12 \cdot 2 \mathrm{mmol} / \mathrm{l}$. Three
Dr Irena Keber, University Clinical Centre, Trnovo Hospital of Internal 1000 Ljubljana, Slovenia. Accepted for publication 8 May 1996 
patients were moderate smokers (up to 15 cigarettes per day). Three patients were treated with lovastatin. One patient had arterial hypertension controlled by enalapril. All patients were free of diabetes and signs of cardiovascular disease.

Twenty eight healthy age and sex matched subjects served as the control group. They were normolipidaemic according to the age dependent recommended values of blood lipids. ${ }^{12}{ }^{13}$ Three were moderate smokers. None had hypertension, diabetes, or a family history of premature ischaemic heart disease, defined as one or more first or second degree relatives with myocardial infarction, angina pectoris, or sudden death before the age of 55 (men) or 65 (women). They were taking no drugs.

Each subject was clinically examined before the study. Systolic and diastolic blood pressures were measured twice with a mercury sphygmomanometer after a minimum of 10 minutes rest. The mean was used in the analysis. Body mass index was calculated from the ratio: body weight/(body height) ${ }^{2}$ in $\mathrm{kg} / \mathrm{m}^{2}$.

Informed consent was obtained from the subjects above 18 years. In participants aged less than 18 years, the informed consent was signed by their parents. The study was approved by the State ethics committee.

\section{CAROTID ULTRASOUND EXAMINATION}

Carotid ultrasound examination was performed using a high resolution $B$ mode Diasonics VST ultrasound system with a $10 \mathrm{MHz}$ linear array transducer. During the examination the subjects lay in the supine position. The $B$ mode scanning protocol involved scanning of the right and left carotid artery. On each side the measurements of the maximum far wall IMT were carried out on three segments, including the proximal $1 \mathrm{~cm}$ of the internal carotid artery, the carotid bifurcation, and the distal $1 \mathrm{~cm}$ of the common carotid artery. Measurements were made by the examiner using the instrument's electronic calipers. The mean IMT was calculated for each patient as the average of six measurements of the maximum far wall thickness in three carotid segments on each side. All measurements were carried out by the same examiner, blind to the clinical and laboratory data of the subjects participating in the study.

The upper normal value of the mean carotid IMT was defined as $0.6 \mathrm{~mm}$, since $95 \%$ of the mean IMT values in controls did not exceed this value. Intima-media thickening was defined as the mean carotid IMT greater than $0.6 \mathrm{~mm}$. Atherosclerotic plaques were defined as focal lesions more than $1 \mathrm{~mm}$ thick.

\section{BLOOD SAMPLING}

Blood for lipid analysis was sampled on two occasions in a period of four to eight weeks and the mean value of the two measurements was calculated. On the second occasion blood samples for the measurements of glucose, $\mathrm{Lp}(\mathrm{a})$, and several haemostatic indices were taken as well. Blood was collected from the antecubital vein between 7 am and 9 am after a
12 hour overnight fast. The second blood sampling was performed after 20 minutes of rest with minimum stasis. Blood for the analysis of glucose, lipids, and $\mathrm{Lp}$ (a) was collected without additives. For the analysis of haemostatic indices, the blood was collected in precooled citrated tubes, placed in ice water, and then centrifuged for $30 \mathrm{~min}$ at $2000 \mathrm{~g}$ and $4^{\circ} \mathrm{C}$. Plasma was transferred to small plastic vials, frozen in liquid nitrogen, and stored at $-70^{\circ} \mathrm{C}$ until analysed. For the assay of $\mathrm{Lp}(\mathrm{a})$, samples of serum were frozen and kept at $-20^{\circ} \mathrm{C}$ until analysed.

\section{LABORATORY METHODS}

The concentrations of total serum cholesterol, ${ }^{14}$ high density lipoprotein (HDL) cholesterol, ${ }^{15}$ triglycerides, ${ }^{16}$ and glucose ${ }^{17}$ were determined by conventional enzymatic assays. LDL cholesterol was calculated from Friedewald's formula. ${ }^{18} \mathrm{Lp}$ (a) was measured by Laurell's electroimmunodiffusion method. ${ }^{19}$ Fibrinogen in plasma was measured as clottable fibrin. ${ }^{20}$ Tissue plasminogen activator ( $t-$ PA) and plasminogen activator inhibitor 1 (PAI-1) antigens in plasma were determined by ELISA methods ${ }^{21} 22$ using commmercially available kits (Imulyse t-PA and Imulyse PAI-1, respectively, Biopool, Umea, Sweden). Plasma t-PA activity ${ }^{23}$ and PAI activity ${ }^{24}$ were determined by chromogenic substrate assays (Spectrolyse/fibrin and Spectrolyse/pL, respectively, Biopool, Umea, Sweden). Euglobulin clot lysis time (ECLT) was determined as described elsewhere. ${ }^{25}$

\section{STATISTICAL ANALYSIS}

Variables showing a normal distribution were expressed as means and standard deviations and differences between groups were tested with Student's $t$ test. Other variables were described by median and range and the differences between groups were analysed by Mann-Whitney U test. For correlation analysis, Pearson's correlation coefficient was calculated for normally distributed variables and Spearman's rank-correlation coefficient for other variables. A possible association between risk factors and mean IMT was analysed by standard multiple regression analysis. The criterion for statistical significance was a $P$ value of less than 0.05 . All calculations were performed by the Statistica computer program (Stat Soft Inc, 1992, USA).

\section{Results}

Table 1 shows clinical data and results of blood tests. Patients with FH had significantly higher systolic blood pressure, and higher concentrations of total cholesterol, LDL cholesterol, and triglycerides. Serum $\operatorname{Lp}(\mathrm{a})$ levels did not differ markedly between the groups.

The mean carotid IMT was significantly greater in patients with $\mathrm{FH}$ than in controls [mean (SD) $0.71(0.15) v 0.49(0.08) \mathrm{mm}$, $\mathrm{P}<0.001]$ as shown in the figure. In the $\mathrm{FH}$ group, 21 patients had increased mean IMT and seven had normal IMT, while in the control group only one subject had an increased 
Graph showing mean carotid intima-media thickness (IMT) in patients with familial hypercholesterolaemia (FH) and in healthy controls. Mean IMT in FH patients was 0.71 (0.15) $\mathrm{mm}$ and in healthy controls it was $0.49(0.08)$ mm [means (SD)] $(P<0.001)$

Table 1 Clinical and laboratory characteristics of patients with familial hypercholesterolaemia (FH) and healthy controls. The age is presented as a mean value and range, total cholesterol, LDL cholesterol, HDL cholesterol and glucose are presented as means and standard deviations, other values as medians and ranges

\begin{tabular}{|c|c|c|c|}
\hline Variable & $\begin{array}{l}\text { FH patients } \\
(n=28)\end{array}$ & $\begin{array}{l}\text { Controls } \\
(n=28)\end{array}$ & $P$ \\
\hline Age (years) & $19.9(11$ to 27$)$ & $20.4(11$ to 27$)$ & NS \\
\hline Sex (male/female) & $12 / 16$ & $12 / 16$ & NS \\
\hline Smoking (number) & 3 & 3 & NS \\
\hline Systolic blood pressure $(\mathrm{mm} \mathrm{Hg})$ & $118(11)$ & $110(11)$ & $<0.01$ \\
\hline Diastolic blood pressure ( $\mathrm{mm} \mathrm{Hg}$ ) & $78(10)$ & $77(10)$ & NS \\
\hline Body mass $(\mathrm{kg})$ & $62 \cdot 4(14 \cdot 4)$ & $64 \cdot 3(13 \cdot 2)$ & NS \\
\hline Body height $(\mathrm{cm})$ & $168(11)$ & $172(11)$ & NS \\
\hline Total cholesterol $(\mathrm{mmol} / \mathrm{l})$ & $8 \cdot 3(1 \cdot 7)$ & $4 \cdot i(0 \cdot 6)$ & $<0.001$ \\
\hline LDL cholesterol $(\mathrm{mmol} / \mathrm{l})$ & $6.5(1.8)$ & $2 \cdot 3(0.5)$ & $<0.001$ \\
\hline HDL cholesterol $(\mathrm{mmol} / \mathrm{l})$ & $1 \cdot 4(0 \cdot 3)$ & $1.5(0.4)$ & NS \\
\hline Triglycerides $(\mathrm{mmol} / \mathrm{l})$ & $0.9(0.3$ to 2.1$)$ & $0.5(0.3$ to 1.0$)$ & $<0.001$ \\
\hline Lipoprotein (a) (mg/l) & $197(0$ to 1130$)$ & $100(0$ to 1348$)$ & NS \\
\hline Glucose $(\mathrm{mmol} / \mathrm{l})$ & $4.8(0.5)$ & $4.8(0.5)$ & NS \\
\hline Fibrinogen $(\mathrm{g} / \mathrm{l})$ & $2.70(2 \cdot 11$ to $3 \cdot 75)$ & $2 \cdot 87(2.11$ to $3 \cdot 48)$ & NS \\
\hline $\mathrm{t}-\mathrm{PA}$ antigen $(\mathrm{ng} / \mathrm{ml})$ & $4.6(1.9$ to 7.6$)$ & $4.3(2.6$ to $10 \cdot 3)$ & NS \\
\hline t-PA activity (IU/ml) & $1.0(0.4$ to 2.5$)$ & $1.0(0.4$ to 3.0$)$ & NS \\
\hline PAI-1 antigen $(\mathrm{ng} / \mathrm{ml})$ & $9 \cdot 2(2 \cdot 1$ to $46 \cdot 3)$ & $8 \cdot 8(2 \cdot 1$ to $35 \cdot 2)$ & NS \\
\hline PAI activity (IU/ml) & $5.6(0.0$ to 31.0$)$ & $6.8(0.0$ to $24 \cdot 8)$ & NS \\
\hline Euglobulin clot lysis time (min) & $202(75$ to 385$)$ & $228(70$ to 425$)$ & NS \\
\hline
\end{tabular}

LDL, low density lipoprotein; HDL, high density lipoprotein; t-PA, tissue plasminogen activator; PAI, plasminogen activator inhibitor.

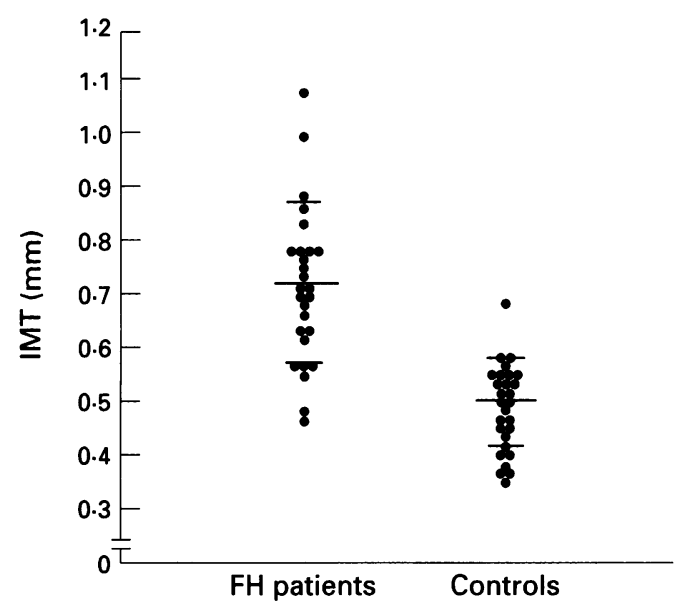

value of IMT. Nine patients with $\mathrm{FH}$ and none of control subjects had atherosclerotic plaques.

Seven patients with FH and normal IMT differed significantly from the other patients only in lower systolic blood pressure values [mean (SD) 111 (9) $v 120$ (11) $\mathrm{mm} \mathrm{Hg}, \mathrm{P}<0.05$ ]. Nine patients with plaques had higher $\operatorname{Lp}(\mathrm{a})$ concentrations [median (range) 552 (19 to
1130) $v 83$ (0 to 982$) \mathrm{mg} / \mathrm{l}, \mathrm{P}<0.05$ ] and lower triglyceride concentrations [median (range) $0.6(0.3$ to 1.9$)$ v $0.9(0.4$ to 2.1$)$ $\mathrm{mmol} / \mathrm{l}, \mathrm{P}<0.05$ ] than other patients with $\mathrm{FH}$.

In controls, males had significantly greater mean IMT than females $[0.53(0.06) v 0.45$ $(0.07) \mathrm{mm}, \mathrm{P}<0.01]$. No such sex dependent difference was found in patients with $\mathrm{FH}[0 \cdot 72$ $(0.17) v 0.70(0.14) \mathrm{mm}, \mathrm{NS}]$.

All three smokers from the control group had normal IMT. Among three smokers with FH, one had intima-media thickening. In the homozygous patient with $\mathrm{FH}$, several plaques were found and the mean IMT was $0.83 \mathrm{~mm}$.

The correlations of mean IMT with some clinical and laboratory variables are shown in table 2. In all subjects together the mean IMT was positively correlated with systolic blood pressure, total and LDL cholesterol, and triglycerides. In patients with $\mathrm{FH}$ the mean IMT was correlated only with age, while systolic blood pressure approached significance. In the control group mean IMT was positively correlated with systolic blood pressure, body height and weight, triglycerides, and t-PA antigen.

The variables that were significant or were

Table 2 Correlations of mean carotid intima-media thickness (IMT) with clinical and laboratory variables in all subjects together and in the group of patients with familial hypercholesterolaemia (FH) and in healthy controls separately on univariate testing

\begin{tabular}{|c|c|c|c|c|c|c|}
\hline \multirow[b]{2}{*}{ Variable } & \multicolumn{2}{|c|}{ All subjects } & \multicolumn{2}{|c|}{ FH patients } & \multicolumn{2}{|c|}{ Controls } \\
\hline & $r$ & $P$ & $r$ & $P$ & $r$ & $P$ \\
\hline Age & $0 \cdot 22$ & $0 \cdot 106$ & 0.38 & $0 \cdot 048^{\star}$ & $0 \cdot 36$ & 0.064 \\
\hline Systolic blood pressure & 0.47 & $<0.001^{\star}$ & 0.36 & 0.059 & 0.40 & $0.036^{\star}$ \\
\hline Diastolic blood pressure & $0 \cdot 13$ & 0.352 & $0 \cdot 15$ & 0.435 & $0 \cdot 11$ & 0.593 \\
\hline Body weight & $0 \cdot 15$ & 0.286 & $0 \cdot 19$ & 0.333 & 0.50 & $0.007^{\star}$ \\
\hline Body height & 0.07 & 0.616 & $0 \cdot 19$ & 0.339 & 0.48 & $0.009^{\star}$ \\
\hline Body mass index & $0 \cdot 17$ & $0 \cdot 208$ & $0 \cdot 14$ & 0.467 & 0.35 & 0.072 \\
\hline Total cholesterol & 0.59 & $<0.001^{\star}$ & -0.05 & 0.814 & 0.04 & 0.849 \\
\hline LDL cholesterol & 0.60 & $<0.001^{\star}$ & -0.02 & 0.916 & $0 \cdot 19$ & 0.323 \\
\hline HDL cholesterol & $-0 \cdot 16$ & 0.228 & 0.02 & 0.911 & -0.28 & $0 \cdot 154$ \\
\hline Triglyceride & $0 \cdot 28$ & $0.038^{\star}$ & -0.21 & 0.296 & 0.40 & $0.036^{\star}$ \\
\hline Lipoprotein(a) & $0 \cdot 15$ & $0 \cdot 281$ & 0.09 & 0.652 & 0.08 & 0.692 \\
\hline Glucose & 0.03 & 0.855 & $0 \cdot 12$ & 0.531 & -0.03 & 0.886 \\
\hline Fibrinogen & $-0 \cdot 11$ & 0.424 & $-0 \cdot 14$ & 0.483 & $-0 \cdot 11$ & 0.587 \\
\hline $\mathrm{t}-\mathrm{PA}$ antigen & 0.23 & 0.086 & $0 \cdot 29$ & 0.132 & 0.45 & $0.017^{\star}$ \\
\hline t-PA activity & -0.04 & 0.773 & $0 \cdot 70$ & 0.726 & 0.07 & 0.724 \\
\hline PAI- 1 antigen & 0.03 & 0.829 & -0.08 & 0.703 & 0.13 & 0.514 \\
\hline PAI activity & 0.01 & 0.928 & 0.07 & $0 \cdot 719$ & 0.18 & 0.353 \\
\hline Euglobulin clot lysis time & -0.04 & 0.781 & $-0 \cdot 12$ & 0.528 & -0.02 & 0.302 \\
\hline
\end{tabular}

IMT, intima-media thickness; t-PA, tissue plasminogen activator; PAI, plasminogen activator inhibitor.

${ }^{\star} \mathrm{P}<0.05$ 
Table 3 Multiple linear regression analysis of six variables in predicting mean carotid intima-media thickness (IMT) in all subjects

\begin{tabular}{lccc}
\hline Variable & Partial coefficient & $P$ & $R^{2}$ \\
\hline Group & 0.78 & $<0.0001$ & \\
Triglyceride & -0.29 & 0.009 & 0.61 \\
Age & 0.22 & 0.016 & $(P<0.0001)$ \\
Systolic blood pressure & 0.21 & 0.052 & \\
t-PA antigen & 0.17 & 0.073 & \\
Sex & 0.13 & 0.196 & \\
\hline
\end{tabular}

t-PA, tissue plasminogen activator.

Table 4 Multiple linear regression analysis of three variables in predicting mean carotid intima-media thickness (IMT) in healthy subjects

\begin{tabular}{llll}
\hline Variable & Partial coefficient & $P$ & $R^{2}$ \\
\hline Sex & 0.47 & 0.003 & 0.47 \\
Age & 0.45 & 0.004 & $(\mathrm{P}<0.001)$ \\
Triglyceride & 0.33 & 0.03 & \\
\hline
\end{tabular}

approaching statistical significance in the univariate analysis were included in the multiple regression analysis. When LDL cholesterol, triglycerides, systolic blood pressure, sex, age, and t-PA antigen were entered into the model, LDL cholesterol $(r=0.56, \mathrm{P}<0.001)$ and systolic blood pressure $(r=0.28, \mathrm{P}<0.05)$ emerged as independent determinants of the mean IMT. This model explained $44 \%$ of the variation of mean IMT $(P<0.001)$. When the group assignment ( $\mathrm{FH}$ or control group) was entered in the analysis instead of LDL cholesterol, $61 \%$ of the variation of the mean IMT $(P<0.001)$ could be explained by the group assignment, triglycerides and age (table 3 ).

The multiple regression model that explained the greatest portion of the variation of the mean IMT in healthy subjects is shown in table 4. Sex, age, and triglycerides explained $47 \%$ of the variation of the mean IMT $(\mathrm{P}<$ 0.001 ).

\section{Discussion}

The aim of our study was to investigate the intima-media thickness of the carotid arteries in young patients with $\mathrm{FH}$ and compare the findings with those of well matched healthy normolipidaemic controls. In 28 healthy controls with a mean age of 20 years the mean IMT was smaller than $0.6 \mathrm{~mm}$ in all but one subject. Therefore the 95 th centile-that is, $0.6 \mathrm{~mm}$-was taken as the upper limit of normal IMT. We could find no published reference values of IMT for this age group. In a study on Eastern Finnish men aged from 42 to 60 years $^{7}$ the average carotid IMT was between 0.53 and $2.25 \mathrm{~mm}$ [mean (SD) 1.02 $(0.28) \mathrm{mm}]$. In healthy Japanese subjects without risk factors for atherosclerosis, aged from 24 to 74 years, mean IMT of 0.59 $(0.15) \mathrm{mm}$ has been reported by Handa et al. ${ }^{8}$

The IMT of the carotid arteries was significantly increased in our subjects, being greater than $0.6 \mathrm{~mm}$ in $75 \%$. In addition, atherosclerotic plaques were found in $25 \%$ of $\mathrm{FH}$ patients, but in none of the controls. In the single study on young FH patients Spengel et $a l^{26}$ reported that $70 \%$ of $44 \mathrm{FH}$ patients aged 2 to 29 years (mean 16.2 years) had carotid plaques detectable by duplex scan, while only $12 \%$ of the controls were affected. IMT was not measured in that study.

In our study $\mathrm{FH}$ patients with normal IMT had lower systolic blood pressure than the FH patients with increased IMT, although all the values were well within the normal range. A tendency to lower values of t-PA antigen and total and LDL cholesterol was also found in FH patients with normal IMT, but these values were not statistically different from the values in other FH patients, perhaps due to the small number of subjects.

Univariate correlation analysis, including both FH and control groups, showed a positive correlation of IMT with total and LDL cholesterol, systolic blood pressure, and triglyceride concentration. Multivariate analysis, including the group assignment instead of the actual values of LDL cholesterol, explained $61 \%$ of the variation of the mean IMT by the presence or absence of $\mathrm{FH}$, triglycerides, and age, but almost all of this explained variation was due to the diagnosis of $\mathrm{FH}$.

IMT in healthy subjects was correlated with body height, weight, systolic blood pressure, triglyceride concentration, t-PA antigen, and marginally with age and body mass index. The intima-media complex was thicker in men than in women. In multivariate analysis only male sex, age, and triglyceride concentration were positively related to IMT. These results provided the expected conclusion that IMT values in growing healthy youngsters depended primarily on body size as determined by height, weight, sex, and age. However, the contribution of several risk factors, even within so called normal limits, was also indicated. Among fibrinolytic variables only tPA antigen, which is believed to indicate endothelial damage, ${ }^{27}$ was correlated with carotid IMT.

Univariate analysis in $\mathrm{FH}$ patients showed only one variables that was related to IMT, which was age. However, t-PA antigen values in the $\mathrm{FH}$ patients with normal IMT were lower than in the other $\mathrm{FH}$ patients. The fact that the IMT was almost independent of anthropometric variables can be explained by the major influence of raised cholesterol on the intima-media thickening: its impact may be so predominant in $\mathrm{FH}$ patients that it masks the contribution of other factors.

We found no correlation between IMT and $\mathrm{Lp}$ (a) concentration. There was also no significant difference in $L p(a)$ concentration between the $\mathrm{FH}$ patients and controls, but $\mathrm{FH}$ patients with atherosclerotic plaques had higher $\mathrm{Lp}(\mathrm{a})$ levels than the other $\mathrm{FH}$ patients. This may indicate that a high plasma $L p(a)$ concentration is not involved in the development of early changes of the arterial wall preceding atherosclerotic lesions but contributes to a faster progression of atherosclerosis. Correspondingly, in another study in subjects with plaques in the carotid arteries detected by Doppler ultrasonic imaging, higher serum $\mathrm{Lp}(\mathrm{a})$ concentrations were found than in subjects with no plaques. ${ }^{28} \mathrm{~A}$ correlation was also 
found between serum $\mathrm{Lp}(\mathrm{a})$ concentrations and coronary artery stenosis documented by angiography. ${ }^{29}$ In the study of Tatò et al ${ }^{30}$ $\mathrm{Lp}$ (a) was found to be the lipoprotein index with the highest discriminative power for the presence of a pathological duplex scan in $\mathrm{FH}$ patients older than 30 years.

In conclusion, young patients with $\mathrm{FH}$ have a significantly thicker intima-media complex in the carotid arteries than healthy subjects. However, individual response is variable and greater than in healthy individuals. Since the increased IMT is considered to be an early stage of atherosclerosis, the regular follow up of IMT changes in individuals at high risk may be warranted. If the association of the increased carotid IMT with atherosclerosis in other vital locations is confirmed in prospective studies, the ultrasound examination of carotid arteries may serve as a non-invasive test to identify those who are more likely to develop premature ischaemic coronary, cerebrovascular, or limb disease, and to monitor the effect of medical intervention aimed at the regression of atherosclerosis during its early stages.

1 Goldstein JL, Brown MS. Familial hypercholesterolemia In: Scriver CR, Beaudet AL, Sly WS, Valle D, eds. The metabolic basis of inherited disease, 6th ed. New York: McGraw-Hill, 1989:1215-50.

2 Pignoli P, Tremoli E, Poli A, Oreste P, Paoletti R. Intimal plus medial thickness of the arterial wall: a direct measurement with ultrasound imaging. Circulation 1986;6: surement $1399-406$.

3 Salonen JT, Salonen R. Ultrasound B-mode imaging in observational studies of atherosclerotic progression. Circulation 1993;87(suppl 2):56-65.

4 Solberg LA, McGarry PA, Moossy J, Strong J, Tejada C, Loken A. Severity of atherosclerosis in cerebral arteries, coronary arteries and aortas. Ann NY Acad Sci 1968;2: 956-73.

5 Schuster HM, Kröner KK, Keller C, Spengel FA, Wolfram $G$, Zöllner N. Atherosclerosis of carotid arteries documented by duplex scan as a predictor of coronary artery disease in familial hyperlipidemias. Klin Wochenschr 1987;65:34-9.

6 Craven TE, Ryu JE, Espeland MA, Kahl FR, McKinney WM, Toole JF, et al. Evaluation of the associations between carotid artery atherosclerosis and coronary artery stenosis. Circulation 1990;82:1230-42.

7 Salonen R, Salonen JT. Progression of carotid atherosclerosis and its determinants: a population-based ultrarosis and its determinants: a population-based

8 Handa N, Matsumoto $M$, Maeda $\mathrm{H}$, Hougaku $\mathrm{H}$, Ogawa $\mathrm{S}$, Fukunaga $\mathrm{R}$, et al. Ultrasonic evaluation of early carotid atherosclerosis. Stroke 1990;21:1567-72.

9 Rankinen T, Väisänen S, Mercuri M, Rauramaa R Apolipoprotein(a), fibrinopeptide $A$ and carotid atherosclerosis in middle-aged men. Thromb Haemost 1994;72 563-6.

10 Williams RR, Hunt SC, Schumacher MC, Hegele RA Leppert MF, Ludwig EH, et al. Diagnosing heterozygous familial hypercholesterolemia using new practical criteria validated by molecular genetics. Am $\mathcal{f}$ Cardiol 1993;72: $171-6$.

11 Thompson GR $A$ handbook of hyperlipidemia. 2nd ed. New Jersey: Merck \& Co Inc, 1994:111-26.

12 National cholesterol education program. Report of the expert panel on blood cholesterol levels in children and adolescents. Pediatrics 1992;89(suppl 3):525-84.

13 Expert panel on detection, evaluation, and treatment of high blood cholesterol in adults. Summary of the second report of the national cholesterol education program expert panel on detection, evaluation, and treatment of high blood cholesterol in adults (Adult treatment panel II). $\mathscr{f} A M A$ 1993;269:3015-23.

14 Allain CC, Poon LS, Chan CS, Richmond W, Fù PC. Enzymatic determination of total serum cholesterol. Clin Chem 1970;20:470-5.

15 Warnick GR, Benderson J, Albers JJ. Dextran sulfate-Mg2 precipitation procedure for quantitation of high-densityprecipitation procedure for quantitation of high-density

16 Fossati P, Prencipe L. Serum triglycerides determined colometrically with an enzyme that produces hydrogen peroxide. Clin Chem 1982;28:2077-80.

17 Passey RB, Gillum RL, Fuller JB. Evaluation and comparison of ten glucose methods and the reference method recommended in the proposed product class standard. Clin Chem 1977;23:131-9.

18 Friedewald WT, Levy RI, Fredrickson DS. Estimation of the concentration of low-density lipoprotein cholesterol in plasma, without use of the preparative ultracentrifuge. Clin Chem 1972;18:499-502.

19 Laurell CB. Electroimmunoassay. Scand 7 Clin Lab Invest 1972;29(suppl 124):21-37.

20 Stevens DJ, Sanfelippo MJ. Evaluation of three methods for plasma fibrinogen determinations. Am $\mathcal{F}$ Clin Pathol 1973;60:182-7.

21 Ranby M, Bergsdorf N, Nilsson T, Mellbring G, Winblad B, Bucht G. Age dependance of tissue plasminogen activator concentration in plasma, as studied by an improved enzyme-linked immunosorbent assay. Clin Chem 1986; 32:2160-5.

22 Declerck PJ, Alessi MC, Verstreken M, Kruithof EKO, Juhan-Vague I, Collen D. Measurement of plasminogen activator inhibitor 1 in biologic fluids with a murine monoclonal antibody-based enzyme-linked immunosorbent

23 Versay. Blood 1988;71:220-5. Wijngaards G. A simple and sensitive spectrophotometric assay for extrinsic (tissue-type) plasminogen activator assay for extrinsic (tissue-type) plasminogen activator applicable to meas

24 Verheijen JH, Chang GTG, Kluft C. Evidence for the occurrence of a fast-acting inhibitor for tissue-type plasminogen activator in human plasma. Thromb Haemost 1984;51:392-5.

25 Keber D, Stegnar M. Exhaustion of arm fibrinolytic potential after repeated venous occlusions and local exercise. Thromb Res 1982;28:693-704

26 Spengel FA, Kaess B, Keller Ch, Kröner KK, Schreiber M, Schuster $\mathrm{H}$, et al. Atherosclerosis of the carotid arteries in young patients with familial hypercholesterolemia. Klin Wochenschr 1988;66:65-8.

27 Tanaka K, Sueishi K. The coagulation and fibrinolysis systems and atherosclerosis. Lab Invest 1993;69:5-18.

28 Költringer P, Jürgens G. A dominant role of lipoprotein(a) in the investigation and evaluation of parameters indicating the investigation and evaluation of parameters indicating the development

29 Dahlen GH, Guyton JR, Attar M, Farmer JA, Kautz JA, Gotto AM. Association of levels of $L p(a)$ plasma lipids and other lipoproteins with coronary artery disease documented by angiography. Circulation 1986;74:758-65.

30 Tatò F, Keller C, Schuster H, Spengel F, Wolfram G, Zöllner N. Relation of lipoprotein(a) to coronary heart disease and duplexsonographic findings of the carotid arteries in heterozygous familial hypercholesterolemia. Atherosclerosis 1993;101:69-77. 